\title{
Changing the narrative: a social reconstruction of anorexia nervosa
}

\author{
Emily Ciabattoni \\ University of New Hampshire, Durham, NH, USA
}

\begin{abstract}
The following article works to externalize anorexia nervosa and reconstruct our understanding of what psychiatry classifies as a mental illness towards a visiting presence. I recognize personal experience as a means to knowing. By analyzing particular artifacts created during the prevalence, distance, and coordination of anorexia nervosa (AN) - I deconstruct societal discourses. This perspective calls us to reconsider other cultural concepts such as control, freedom, etc. In the end, I propose that recovery requires the coordination of multiplicities in which AN is kept in conversation and balanced with other discourses - rather than severing AN's voice completely.
\end{abstract}

\section{Introduction}

\section{A narrative of anorexia nervosa}

I don't know why I feel so down. I shouldn't, considering how lucky I am. There are so many opportunities available to me and I'm very privileged. I feel like I don't have any friends and that something is wrong with me. How do bullied people survive?

Words that come to mind: gone, spirit, die, heart, love,

Correspondence: Emily Ciabattoni, 43 Harmony Crossing, East Bridgewater, 02333 MA, USA. Tel: +1.612-388-8476.

Email: emmyciabattoni@gmail.com

Conflict of interest: there were no relevant financial associations with this article. However, it might appear that the heavy, historical blame cast on the mother-daughter relationship in regards to eating disorders influenced the portrayal of my mother - as not overly involved and therefore innocent. I have entertained this possibility but adhere to what is written - and as written, my experience remains true. In comparison with my friends' moms, my aunts as mothers, and my grandmother as a mother, my mother exists as relatively less involved.

Key words: Anorexia nervosa; Social construction; Narrative.

Dedication: this is dedicated to Dr. Sheila McNamee for her inspiration and guidance; to Maz for always believing in me; and to both of my parents - for their greatest efforts in raising me to be the best I can be.

Note: presented at University of New Hampshire's Undergraduate Research Conference 2016.

Received for publication: 2 November 2016

Revision received: 7 February 2017.

Accepted for publication: 8 February 2017.

This work is licensed under a Creative Commons Attribution NonCommercial 4.0 License (CC BY-NC 4.0).

CCopyright E. Ciabattoni, 2017

Licensee PAGEPress, Italy

Qualitative Research in Medicine \& Healthcare 2017; 1:51-62 doi:10.4081/qrmh.2017.6367 selfish, why, light, dark, wrong, alone, problems, escape, psycho, worth

What's wrong? Do I not have friends? Is there something very wrong with me..... am I wrong? Did I do something very 'wrong' because I feel like I did. I'm not sure that I'm worthy. Am I living for others? That's kind of conceited to think... But I can't think for myself? I can never make decisions. I'm genuinely worried about losing my mind and myself. I'm scared... what if I become psycho? I don't know what's wrong and I don't know how to fix it. My own thoughts are scaring me. My nightmares scare me. Am I scared of myself?

Maybe because I put so much emphasis on being good. I put so much of myself, all of myself, into being good. Now, it seems that the world might not value goodness. What is goodness worth? (Figure 1).

\section{Living with anorexia nervosa}

I was deteriorating; throughout my freshman year at college, I dropped from 125 to $93 \mathrm{lbs}$. I unwillingly agreed to participate in an outpatient therapy program at Water's Edge Counseling and Healing Center in Burnsville, MN. A family friend later confided in me-your mother thought she was watching you die; the mortality rate of $\mathrm{AN}$ is from between five to twenty percent. ${ }^{1}$ The program ran from Monday to Thursday, 8:30 am to 2:30 pm. The length of weekly duration depended on my speed of recovery; which meant a healthy weight and mentality approved by a team of counselors. I stayed for about three months. The Adult Intensive Program for Eating Disorders used Cognitive Behavioral Therapy-Expanded (CBT-E), Acceptance and Commitment Therapy (ACT) and Life Skills (similar to those of DBT); the program also provided education, skills teaching, meal support, nutrition education, somatic resourcing, spiritual guidance, and movement therapies. ${ }^{3}$

\section{Before anorexia nervosa}

Before moving away for college, my way of being in the world did not seem as problematic or out of control. 
Although dangerous discourses circulated, I was involved in multiple communities and exposed to various discourses. I had developed a network of people, places, and things that checked and balanced each other; surrounded by people I loved and things I loved to do, I had access to multiple generative discourses and vitality. I could almost always find a level of security and affirmation in someone's voice or relationship. My environment felt dynamic yet balanced; and constructed an overall fulfilling way of being.

Of course, my childhood was not perfect; my parents fought and divorced in high school, my father exercised authoritarian control, etc. Sometimes I struggled with the heavy-weighted discourses of health, athletic excellence, restriction, small, silent, and perfect; but these discourses seemed to exist on more micro levels. When these discourses amplified power and stole the show-they demanded a most submissive way of being.

\section{Moving away}

When my environment changed, everything changed. AN visited me harshly when I felt most isolated and alone; or I felt most isolated and alone when AN visited harshly (I'm not sure). I moved away from home in Prior Lake, MN to attend college in the city. Uprooted from my life and without a supportive network in place for coping, I struggled to shift my way of being. I scavenged for any kind of guidance; as the daughter of a patriarchal family, I sought demands - demanding voices. I became susceptible and submissive to dominant discourse. I engaged in restriction, smallness, health, athletic excellence, and other heavy-weighted discourses I had previously depended on - without the means to check and balance with healthy presences and discourses surrounding me. While searching for guidance, I felt the dominant systems more deeply than ever before-and religiously participated in them as if they were my familial pursuit towards health or figure skating career.

My way of being strove for something big, something powerful; something I wasn't aware of and never questioned. I strove for the good-for the dominant. And in the city-the good was on billboards, magazines, highprofile professors, everywhere. A chaotic, political war took place - set at the site of my self. AN policed my body and struggled for control. Although other discourses fought for a say, policing didn't allow it - policing only allowed the good.

\section{A relational exploration of anorexia nervosa}

I wrote the previous diary entry in the presence of AN [anorexia nervosa]. The narrative holds potential for relational exploration; it illustrates and reflects multiple societal constructions of AN. Whether it's a problem within the self, an obsession with what's good, or being lost in

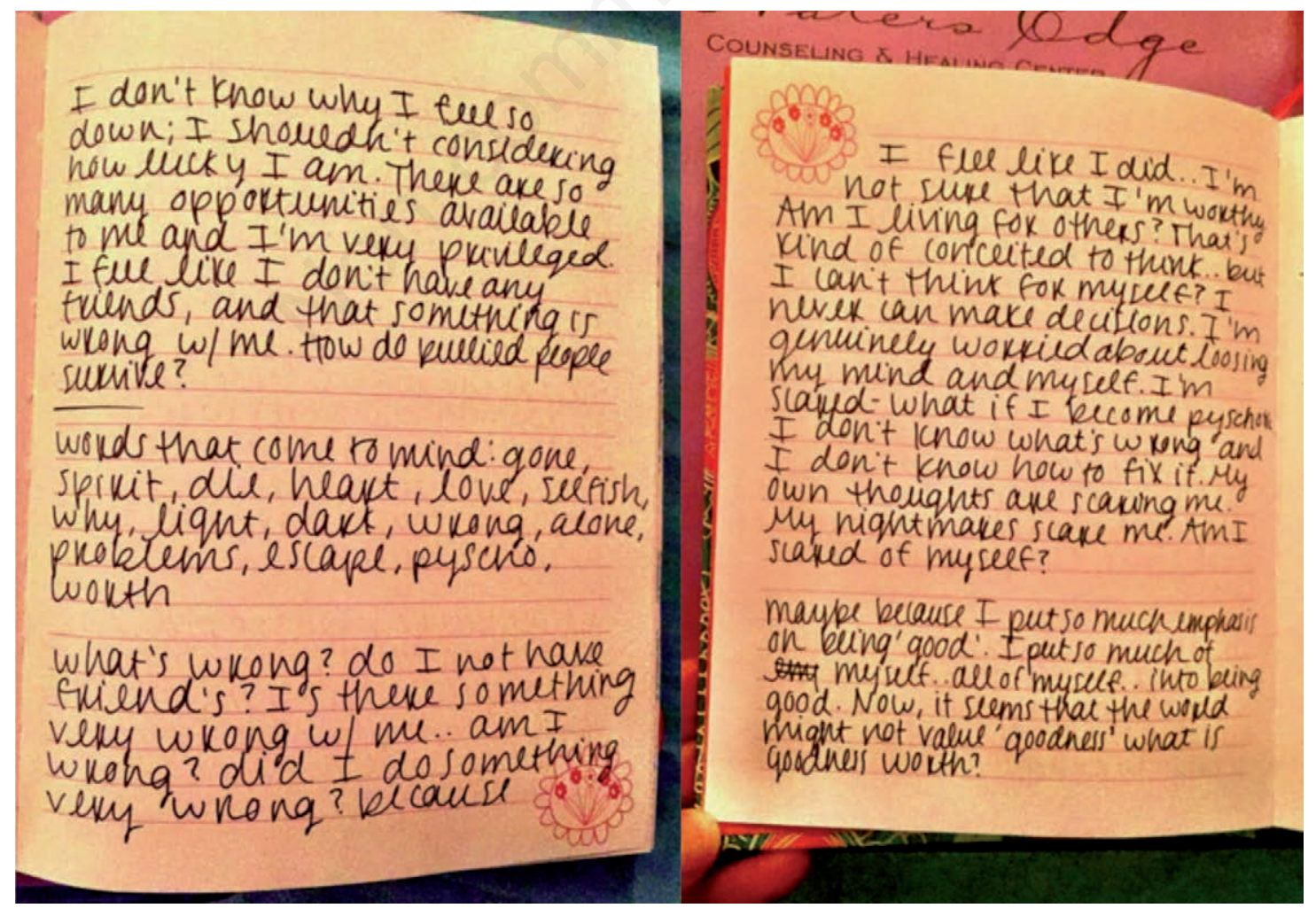

Figure 1. Journal entry written during my freshman year of college in the strong presence of anorexia nervosa. 
an isolating spiral of questions, this way of being is an active product of and agent within our environment.

AN serves as a psychiatric diagnosis meant to classify a mental illness; in which the problem lies within the mind of an individual. But through a relational perspective, AN exists differently. AN existed as a product of my environment - a way of being in society developed by grander societal systems; because it imitated these systems. AN also existed as an agent within my environment-in which it further perpetuated and constructed systems. As socially constructed, AN did not exist as a mental illness inside of me; AN became a problematic presence of its own.

An understanding of AN as a socially constructed product relieved me - it might've even healed me. It lifted the weight from my shoulders, extracted the strain of evil from my veins. It felt like maybe, it wasn't all my fault. When it was my fault - and meanwhile, I was starving the label became a growing burden on a deteriorating body. I not only scavenged the strength to fight for wellbeing, but was forced to maintain the strength in bearing the social consequences.

Lock et al. ${ }^{1}$ encourages externalization as a means to understanding - By separating anorexia from the person, it becomes possible to ask about anorexia's tactics of voice, about its rhetorical strategies, the moves it makes, its attempts to cover its tracks in order to deny its effects ( $\mathrm{p}$. 267). Understanding can lay a solid foundation for recovery; April Chatham-Carpenter ${ }^{2}$ testifies, Separating out my voice from the voice of anorexia seemed to give me the freedom to choose which voice to listen to and 'obey'.

Acquaintances to AN commonly refer to its voice ${ }^{1,2-9}$ - like it's some kind of presence that solidifies unworthiness and fuels starvation. Similar to other acquaintances of AN, recovery didn't demand severing AN's voice completely, ${ }^{1,2}$ recovery meant learning to live in relationship with the voice through environmental re-creation. Environmental recreation encompassed my coordinated actions and relationship with self, others, activities, communities, values, beliefs, etc. Environmental re-creation encouraged me to alter my entire way of being in the world.

I explore my family, school, figure skating, and college environments because I spent the majority of my life in these communities; the heavy-weighted discourses that constructed these environments constructed me as well. I examine various artifacts - a diary entry written in the heavy presence of AN, a recording of a vivid nightmare, and three therapeutic drawings. I examine each artifact as a window into my relationship with AN-I ask: considering my relationship with $\mathrm{AN}$ at that time, what insight does each provide about AN's way of being?

By deconstructing heavy-weighted discourses that constructed my way of being - health, athletic excellence, restriction, smallness, silence, perfection-I discover discursive systems in which AN thrived. With this understanding, I offer personal and clinical strategies meant to discourage AN's way of being. Following, I describe how AN seemed to mimic grander societal systems - through ideology, policing, security, and isolation. By reconstructing some core cultural concepts, I believe we could discourage AN's way of being and eventually-destructive societal systems. In conclusion, I offer the concept of $\mathrm{co}$ ordinated multiplicities as a tool to create another way of being. Below I offer an outline meant to guide the reader through my relational exploration of AN.

I. Discourses
A. Health
B. Athletic Excellence \& Restriction
C. Small
D. Silent
E. Perfect

*By deconstructing the heavily-weighted discourses that illustrated and constructed my way of being with $\mathrm{AN}-\mathrm{I}$ discovered systems in which AN was allowed to thrive. Following, I offer strategies meant to discourage AN's ways of being.

\section{Personal and Clinical Strategies}
A. What is health?
B. Image Overload
C. The Importance of Deviance
D. The Good

*These strategies call us to reflect on society - and more specifically, how AN seems to embody even grander societal systems.

III. The Ideal
A. Policing
B. Security
C. Isolation

1. smothering the multi-being

*I offer reconstructions of cultural concepts meant to discourage AN's way of being.

IV. Conceptual Reconstructions
A. Control
B. Mother \& Daughter
C. Intelligence
D. Deviance

*How can we use these concepts to create ways of being that discourage $\mathrm{AN}$ and the societal systems it perpetuates?

V. Another Way of Being
A. An Illustration of Being with AN
B. An Illustration of Coordination of Multiplicities
C. My Story

Throughout this reflective journey, I aim to fill the gap in AN research by offering the patient's perspective. As a former patient, I recognize personal experience and narrative prose as a means to knowing. My thoughts, feel- 
ings, and understandings are the hardest to deconstruct; it's hard to realize how my way of being, which seemed so private and individual, was actually a product of and response to my environment. I present the symptoms associated with AN as developments constructed by a way of being in the world; the narrative of this way-of-being could be recreated as a means to recovery not only on an individual level, but on a communal level as well. I hope that my story will create sense for others who are struggling to find their own ways of being with AN.

\section{Discourses}

I examine personal experiences of heavy-weighted discourses within the following environments: family, school, figure skating, college, therapy. The discourses that ran throughout my family were not intentionally harmful; they were discourses that have been at work constructing American-patriarchal families for decades. These discourses were societal, traditional, and normal- they run through many other American families today. I truly believe that my parents raised me to be the best I could be in the ways they knew how. They deeply cared and I am greatly appreciative. However, throughout my family, school, figure skating, and college environments - heavily weighted discourse existed as dominant discourse. I examine the following dominant discourses to explore and more deeply understand AN's ways of being.

\section{Health}

The Rules-

- no hydrogenated oils

- no sugary cereal (unless mixed with a healthy one)

- no juice (unless watered down 1/2)

- 1 treat per day: snack-size candy bar, ice cream treat, cookie

- 1 extra per day: jelly, yogurt, syrup, sugary cereal

Dad! Dad! Can we get this? If it was under 12 grams of sugar with no hydrogenated oils, the outlook was promising. Every once in awhile we'd disregard the rules for a pack of Klondike bars on sale or vanilla pudding specials - so I didn't feel deprived. But my friends' moms let them eat candy without supervision, so whenever my brother and I went over there- I'd stuff myself with a minimum of six pieces.

My family was health-conscious; we limited unhealthy food as a means to health. Although our list of rules was detailed, it didn't feel extreme. I felt healthy. We were an active family - always outside, swimming, or playing sports. My parents' approach to health likely came from their careers as athletes: my mom a gymnast, my dad an avid tennis player. The health discourse tends to run heavy in sports - with themes of limitation as a means to health and athletic excellence.

\section{Athletic excellence and restriction}

$$
\begin{aligned}
& \text { More rules- } \\
& - \text { no white bread } \\
& - \text { no fried foods } \\
& -\quad \text { lots of water }
\end{aligned}
$$

I stared at the menu on the red and white checkered tablecloth in utter devastation. Fried chicken or fried fish. Seriously... no other options??? At the famous fried chicken place across the border in Illinois, my family seemed to understand when I peeled the fried skins off my fish dinner- I was dedicated to the pursuit of athletic excellence.

Although the competitive figure skating list wasn't as detailed, it was religion; and athletic excellence went hand-in-hand with restriction. Furthermore, it implied thinness. A pound lost or added - the little dress was merciless. My competitors could see it. My coach could see it. The judges could see it. And in a highly competitive environment, everyone was watching. But when I left for college, and moved away from my family and figure skating community, another list of rules developed - but this time, who was watching?

\section{Small \\ AN's Rules- \\ - no hydrogenated oils \\ - no sugary cereal \\ - no juice \\ - no treats \\ - no white bread \\ - no white carbs \\ - no fried foods \\ - lots of water \\ - breakfast: $1 / 2$ cup granola \\ - lunch: 1/2 cliff bar, handful pistachios \\ - dinner: not too much}

But the smaller she gets, the tighter her skin pulls-the more her skin encourages her to stay small, get smaller. And the tighter it's pulled to her body, the more she comes together. She feels held, in a comforting, secured way. She's secured. By her skin. By the feeling. Small.

*written during therapy

The restriction discourse permeated the majority of my childhood - threaded with implications of health, athletic excellence, and overall-thinness. These concepts became interchangeable definitions in and of each other. Small became a dominant discourse and priority. I utilized restriction to shrink myself; but more importantly, to better myself.

\section{Silent}

Small existed not only physically, but figuratively as well. As the daughter in a traditional, patriarchal family, I 
was expected to be small and silent under authority. The paternal side of my family highly values the silent presence of children and commonly considers questioning as talking back. The silent discourse forbid complaining and negative talk; communicative strategies that work towards change and countering dominant discourse.

The silent discourse was prevalent not only at home, but in school, too- - where I existed as the shy kid among peers I'd known for nine years. In class, the teacher-the face of authority - was always watching and supervising. To be good I remained silent. Once labeled shy, I latched to that identity - and so did the other kids. At anytime, I could've changed things-I could've spoken out, or raised my voice, or started talking to someone. But I didn't. Once I internalized the label, that reality didn't exist for me.

If I would've spoken out, or made a joke, the other kids would've been seriously surprised - and I know this because it happened. With my close friends, I'd get loud. And if the other kids heard me, they'd freak out-OMG I haven't heard your voice that loud before! No, no, it's good! Most of the students supported me breaking out of my shell — but they also drew more attention to me. When they noticed me, I noticed I wasn't being quiet anymore. And the discourses deduced that I wasn't being good. Most of the time, the good felt limiting. Regardless, I strove for it - even if that meant missing recess to an extra 45 minutes on a coloring assignment. I looked for, listened to, and internalized the good; I never questioned it. And under the authority of AN, I did the same.

\section{Perfect}

After completing the list of chores, I waited for my dad to evaluate each item. While he scanned my bedroom, the living room, the kitchen - I anxiously peered behind him. Fingers crossed I didn't miss a single scrap. if we left an item, it wasn't clean at all; if it wasn't perfect, it was imperfect. Perfection allowed for only one way of being.

Perfection itself could be understood as a heavilyweighted dominant discourse; which constructs one good and lots of bad. Perfection perpetuated throughout my figure skating career. Physically, the blades weren't forgiving - do it their way, with little margin, or you're likely flat on the ice. Jumps, edges, and spins were all judged and evaluated by the book - the one way, the perfect way. Discourses of 'ideal' circulated throughout the figure skating community in various dimensions; the priority of perfection permeated on and off ice practice, eating habits, sleeping habits, mental/cognitive training, relationships, etc.

Within the figure skating environment, everyone seemed to speak the same ideological discourses - continuously adding weight to these ideals. In the presence of AN, I practiced restriction as perfection - this singular good, this singular way of being, enabled whatever means possible to achieve it. Personally, perfection began to walk hand-in-hand with the good. I thought that in order to be good, I must be perfect-and both concepts held their own casts of synonyms, definitions, and ideologies.

\section{Personal and clinical strategies}

AN's way of being was not developed by these five discourses alone. Societal systems that encouraged heavily-weighted dominant discourse to construct my environment seemed to enable AN's way of being. As mentioned, I participated in a three-month outpatient therapy program-I was one of about fifteen adult patients who struggled with eating disorders, anxiety, and depression. Overall, the center did wonders for my recovery; it created a temporary environment in which I learned another way of being in the world. Throughout therapy, the following ideas ignited change and fueled recovery. These sections are not directly intended as criticism; rather a toolbox in which to draw instruments for change.

\section{What is health?}

What is health and how is it illustrated? Understandings of health seem to come from a combination of discourse and bodies-which commonly manifests in images. Images of the body exist walking around us, on the big screen, in magazines, and through the infamous, pervasiveness of advertisements. Ads don't only sell products and concepts; ads sell normalcy. ${ }^{4}$ What's normal becomes what's seen and what's abnormal is less seen. But with an overabundance of advertising at our fingertips and every turn of the head - the ideal, photographic body becomes normal, attainable, and even healthy. The image is thrown at us without any understanding of the processes involved in getting there. Asking the question what is health could aid in recovery; answers might reveal definitions, synonyms, antonyms, and ideologies attached to an individual's understanding of health.

\section{Image overload}

The prevalence and overabundance of the ideal, photographic body invites us to merely look at it. Which seems harmless - what's the harm in viewing a photograph? According to Jean Kilbourne ${ }^{4}$ in Killing Us Softly 4 , almost everyone feels personally exempt from the influence of advertising. But by merely looking at idealistic bodies, we accept them; we don't realize the influence because only $8 \%$ of ad messages are received by the conscious mind - the majority of advertising works on a subconscious level. ${ }^{4}$

In accepting a particular image, we accept a reality. Kilbourne ${ }^{4}$ illustrates the power of advertisements in which they create an atmosphere of standards and expectations that we swim within; furthermore, the reign of these images act as dominant discourses. Sontag, ${ }^{5}$ a respected photography critic, refers to the superiority of the photograph as the dominant and most natural way of re- 
ferring to appearances. The unquestioned pervasiveness of the photographic body embodies a dominant discourse - and demands the way to be.

So dominant discourse can become tangible, strong, and maybe even normalized through the photographed body - without words and an obvious means of questioning. Furthermore, the extreme ambiguity and limited context of public photographs invite false interpretations; false realities. The camera may lie through edit, retouch, Photoshop, and staged juxtapositions. The fake photograph - the one we might never notice, only merely look at - can falsify reality. ${ }^{5}$ These unrealistic images of what we should be seem to justify whatever means necessary in achieving that image. In an image saturated worldwho knows what we agree to upon viewing the photograph without question.

\section{The importance of deviance}

Dominant discourse seems to condemn deviance; but its importance should be recognized. Without deviance, there would be neither options nor alternative discoursejust assimilation. Denying deviance would deny change and difference. Furthermore, deviance multiplies possibilities, potentials, and vitality. ${ }^{6}$

If deviance didn't exist, society would forever function at the will of the dominant - at the will of the empirical. Empiricism as perfection heightens pressure on standards and expectations. Although objective and classifying, Garner's ${ }^{8}$ Development and validation of a multidimensional eating disorder inventory for anorexia nervosa and bulimia study concludes that a sense of ineffectiveness sets AN acquaintances apart from weight-concerned females. Perfectionism, because unattainable, could fuel this sense of ineffectiveness. ${ }^{8}$ But we don't have to exist in the empirical, perfect manner; rather than prioritizing the empirical answer, we could encourage deviant and different answers. If we recognized the multitude of right ways instead of the lonely one-pressures on standards and expectations might lighten.

Therefore, how could a child be taught the importance of deviance? How would a traditional Western family restructure to not only support the authoritarian voice, but give rise to multiple voices? How would AN reconstruct its way of being when confronted by deviance? Personally, partaking in a vast array of experiences such as painting, drawing, yoga, hiking, camping, travelling, meeting new people, trying new foods, etc. were my first steps in breaking free from AN's rigid regime. I began another way of being filled with variety and vitality that steered me away from AN's strict way of being. Deviance encouraged me to open my eyes to the worlds beyond dominant discourse.

\section{The good}

Throughout therapy, we listed good and bad foods and deconstructed the dichotomy. But AN encompasses a greater good - a good that transcends food groups. As a means to healing, one might ask: what is your good? By listing synonyms, writing definitions, and/or drawing pictures of a more general good - one might become more aware of additionally constructed discourses and meanings. Awareness of what is good, and the sources that construct that good, could empower the person and offer a starting point for change. Personally, throughout recovery, I reconstructed my understanding of the good into $a$ good-in which there were multiple goods. Food became $a$ good through sharing meals and as a medium for socialization. Health became $a$ good that meant taking care of my body.

Good varies from person to person; what's good varies depending on relationship, community, and environment. But when a good transforms into the good - the good becomes idealistic and dominant discourse. Dominant discourse limits what's good to one way-and exists as an ideology. Like dominant discourse, the ideal exists unquestioned and just the way it is.

These strategies call us to reflect on society-and more specifically, how AN seems to embody even grander societal systems.

\section{The ideal}

The ideal seems to be our dreams, hopes, and wishes - the ultimate good. But it's more than that. Throughout history, the ideal has invited dividing societal practices. According to The Image of Objectivity, ${ }^{9}$ the ideal sets standards and expectations. Julie Hepworth ${ }^{10}$ in the Social Construction of Anorexia Nervosa makes sense of disordered eating practices as resultant from complex sets of standards and expectations. The ideal deems the perfect $v$ s typical - and encourages striving for the perfect, the ideal, the one way, rather than recognizing possibilities. The perfect vs. typical serves as a dichotomy-a separating and other-ing tool; similar divisive practices seem alive and at work in AN. Throughout CMN 742: Communication, Pathology, and Identity (Spring 2016) course with Dr. Sheila McNamee, the following concepts aided my continued recovery and helped make of sense AN's way of being in relationship with societal systems: discourse, deviance, ideal, policing, security, isolation, freedom, connection, control, blame, intelligence, and the coordination of multiplicities.

\section{Policing}

Societal systems have relied on policing to preserve the ideal. Hepworth ${ }^{10}$ speaks to anorexia and policing one's body as disciplinary practices of self-surveillance to preserve dominant discourses/norms. AN might police by searching for fat, obsessively surveilling mirror/camera images of the body, exercising as punishment, etc. AN's policing practices reveal thinness as a dominant discourse; but in order for AN to police, dividing practices must be exercised. 
Policing deems the virtuous $v s$ non-virtuous. ${ }^{11} \mathrm{AN}$ deems specific parts of the self virtuous - such as (personally) active, disciplined, restrained; and other parts non-virtuous - such as (personally) lazy, rest, relaxation, dependence. Policing one's body implies policing one's self-inviting self-polarization. Within the self, we strive for consistency and coherence-in which our inner dialogue resonates with environmental discourses; ${ }^{7}$ therefore, the divided self invites a state of turmoil and chaos.

In policing, with polarization comes elimination. ${ }^{11}$ Policing has been exercised to eliminate the most destructive actions; which radicalizes AN's non-virtuous qualities as criminal. However, in singling out particular actions, we place a label on these actions - we limit these actions as non-virtuous, as criminal, when these actions might become virtuous in other contexts. Regardless, policing requires the elimination of deemed actions, which invite further conflict, chaos, war, and ultimately defeat - within the self and body.

We might recognize policing as not only a practice, but an overarching and encompassing term - a way of being. Foucaul $\mathrm{t}^{12}$ refers to policing as a term whose meaning embraces all the process of human intercourse, exchange, circulation and cohabitation within a governed population - policing might fuel dividing, isolating, and ideal discourses to construct a particular way of being in the presence of AN.

In the presence of AN, as illustrated above, I felt a serious internal struggle - as if something was wrong with me. Something was wrong with me, and I couldn't eliminate it. I strove towards goodness by policing my every action. Down to the last bit of food in my mouth, to the extra skin on my stomach, to the way I answered questions in class-I was constantly policing towards perfection and couldn't reach it. I was exhausted and defeated. This state of utter turmoil, failure, and confusion manifested in nightly terrors. When I fell asleep, non-virtuous and virtuous co-existed in vicious interactions of policing, combat, elimination, and defeat.

\section{Security}

Her body soaks into the sheets. That little bulge, that little addition to her. It hangs there, somewhat distant, alienated, on her lower stomach. It's not supposed to be there. She tries not to look at it, but she gives in every time. Is it still there?

The comforter weaves between her legs, over and under her arms, across her back. It winds around her torso, the sheets disguise her; that extra bit of stomach folds into the sheets. It's almost not a part of her anymore.. she wishes it would leave and attach to this blanket world. But it won't leave her alone.

*written in therapy

Other than to preserve and perpetuate the ideal, policing has served a more positive societal functionsecurity. ${ }^{12}$ According to Foucault, ${ }^{12}$ law depends and orients around security; which illustrates policing as an agent of security (by protecting the law). Foucault ${ }^{12}$ explains that qualities like abundance, sustenance, and equality are all momentary - they may apply to that moment only. But security implies extension in point of time; a promise. ${ }^{12}$ I clung to AN as security and promise - in which policing towards thinness and perfection would guarantee a better way of being. Like policing towards civil responsibility guarantees a better way of being. Maybe this promise, this extension beyond time, allows the body to endure the starvation state - in the understanding that, no matter the present moment's condition, policing will ensure freedom from the non-virtuous. Overall, a promise of security underlies AN's policing; which encourages someone to hold on, despite participation in a self-defeated way of being.

\section{Isolation}

How do people become so inflexibly committed to a self-defeating way of being? Let us place this question in the context of multi-being. As outlined earlier, normal life equips us with innumerable potentials for relating. However, in this case we confront people whose patterns of action are narrowly constrained. Rich potentials remain unrealized. We often view such persons as problematic personalities: Jack is aggressive; Jill is a chronic depressive. This is to mistake the self of the moment for the potentials in waiting. If our potentials for action originate in relationship, so must we turn to relationship to understand the origins of constriction. There are two major forces at work in such cases. The first may be located in ongoing relations in which the person is immersed, and the second in the past history of relationship. ${ }^{7}$

Hepworth ${ }^{10}$ explains AN as a self-contained worlda world of isolation. Isolation seems to defy Gergen's ${ }^{6}$ way of being which emphasizes the person as a multibeing; in which we are different selves with different people. Potentials are infinite in relationship-Existence in relationship ultimately gives rise to an enormous reservoir of inchoate potentials for action ${ }^{7}$ (p. 133). Furthermore, the self is constructed through interaction, and we gain access to potential through these interactions. Co-actions have the ability to shape, diminish, and expand potential - and these potentials create a sense of vitality in our lives. ${ }^{7}$ Vitality comes from difference - the ways in which we coordinate, relate, interact and co-create life together; vitality comes from a confluence of these relationships in which one body houses multiple identities, voices, relationships. ${ }^{7}$

\section{Smothering the multi-being}

AN deemed the ideal discourse virtuous and other discourses non-virtuous. Although AN deemed eating non-virtuous, other discourses said differently; for example, eating could be considered virtuous as a social activity in sharing 
a meal. Quietly, counter voices existed: voice \#1 might grumble hunger cues, but AN would interrupt and say it's not legitimate. Voice \#2 might be a friend offering a cookie she just baked, wanting me to try it; but AN invalidated that voice, too. In order for AN to become that one, singular, authoritative voice - it had to be able to debate and counter every other voice and discourse. AN had to be dominant.

AN bounded my being through isolation and the embodiment of dominant discourse. When AN was present, I was not a multi-being. It's voice was the only voiceand it remained dominant, unquestioned-demanding my obedience. I heard the other discourses, the other voices of family, friends, coworkers - but they were submissive. In AN's presence, I was not a daughter, a best friend, or a writer-I was not a multi-being. I was the ideal.

According to the MayoClinic ${ }^{13}$ online medical dictionary, social withdrawal is an emotional and behavioral symptom of anorexia nervosa; which implies that isolation is prevalent in diagnosed cases of AN. Isolation, a seemingly common pattern in AN's presence, restricts, limits, and narrows not only eating habits but relationships. AN felt most able and alive in isolation; in my particular case, I never had trouble eating with friends. But when I was alone. I wouldn't eat. I'd restrict.

Coordinating with others invited alternate discourses - discourses that work to counter and degenerate AN's dominant reign. When with my friends, they would tell me to eat, or order us fries to share. I felt socially obligated to participate in the feeding process with my friends; I wanted to participate-I wanted to coordinate my actions and align with people I loved. AN depended on limiting relationships, potentials, and anything unknown in order to preserve the ideal.

While preserving AN, I squandered difference. According to Gergen, difference creates life, meaning, and vitality. ${ }^{7}$ Through isolation, AN distanced and detached me from society, meaning-making, and vitality. The following is a step-by-step illustration of how isolation might manifest in a self-defeated way of being. I created this formula to visualize the connections between co-action, potentials, vitality - and ultimately, self-defeat:

1) Co-action shapes, diminishes, expands potentials

2) Limit co-action=limit potentials

3) Limited potentials $=$ limited vitality

4) Limited potentials + limited vitality $=$ self-defeating pattern

Although distancing, isolation is active and participates with society. Isolation as coming into oneself is not an individual act - it's a social act of distancing oneself from society and the other. AN could be explored as an embodiment of the ideal - in which it exercises systems such as division and isolation as a means to preservation. AN could be explored as a rejection of society - in which isolation attempts to remove the individual from society. AN seems to both embody and reject an ideal; striving for the black vs. white, either/or philosophy-diminishing difference. In this manner, isolation interacts degeneratively (it limits and restricts coordinated actions).

\section{Conceptual reconstructions}

I offer reconstructions of cultural concepts meant to discourage AN's way of being.

\section{Control}

Generally, society has practiced policing and isolation as a means of control to preserve ideals. However, the cultural emphasis on control seems to have created a paradox between freedom and connection. The individualistic perspective understands freedom as free from others- free from their wishes, wants, demands - which exercises divisive practices (self from others). But as human beings, we long to connect.

In an individualist society, we also praise independence. Independence invites elements of separation and control to find a way of being in the world independent from others. The struggle for independence and control seems most prevalent during adolescence - illustrated through the statistic about one out of every one-hundred young women between ten and twenty are starving themselves ${ }^{14}$ - an age of becoming independent. AN has been understood as a denial of autonomy or regression into childhood where the physical body remains childlike and underdeveloped (starved). ${ }^{10}$ There's an interesting paradox in AN as well-with AN, one might deny food as a means to independence; however, in the end, this practice usually renders the person more dependent than ever. ${ }^{10}$ Historically, the heavy-weighted discourse of control seems to rule, confuse, and further perpetuate oppressive systems.

I drew this picture (Figure 1) in therapy. Grounded but wild/free speaks to my struggle for control. Roots connect my feet to the ground and imply a desire for belonging; but my head is with the leaves that fly free in the windI also yearn for freedom (Figure 2).

So how does one be free from others, yet fulfill the human desire for connection? Lightening the cultural emphasis on control might empower the individual in developing his/her way of being through a balance of agency and obligation. Shifting our focus from control to finding a more fulfilling way of being might also ease the discomfort in change, difference, and environmental shifts. Also, by learning to find comfort in uncomfortable situations, we might loosen our grip on control.

\section{Maybe life should be yoga}

If we approached life like yoga, or a wave, it might be easier. Whether it's yoga or surfing, we put ourselves in uncomfortable situations-a twisted pose or the face of a monster swell. But we deal with it. With breathing, or sheer panic, we learn to overcome that discomfort-to maybe even take advantage of it, to take it for a ride. We work with 
it. We find ways of being with it-discomfort. Uncomfortable, unpredictable, uncontrollable. Situations that might steer us clear of dangerous, cyclical patterns. Comforting cycles that form habits and zones and limit us- limit our vitality. In uncomfortable situations, we have to accept changes, problem solve, and go with the flow-opportunities for diverse thinkings and re-creations in order to survive. And with these diversities, comes vitality.

${ }^{*}$ written in distance and recovery from AN; letting go of control

As a society, we could shift our focus from control to finding a more fulfilling way of being in society. By shifting my emphasis from control to finding a more fulfilling way of being, I began to realize the ways in which I was connected but free. I try to conceptualize my self as a leafattached to the branch, yet flowing freely in the wind. With this understanding I am somewhat connected and somewhat free. I've grown away from control and towards an awareness of agency and obligation when attending to my environment; in which a fulfilling way of being strives for balance between the two. I strive for a balance between the branch and the wind. And if flowing free means breaking free-I might eventually come full circle: settling in the ground to nourish a future tree. For example, I struggled

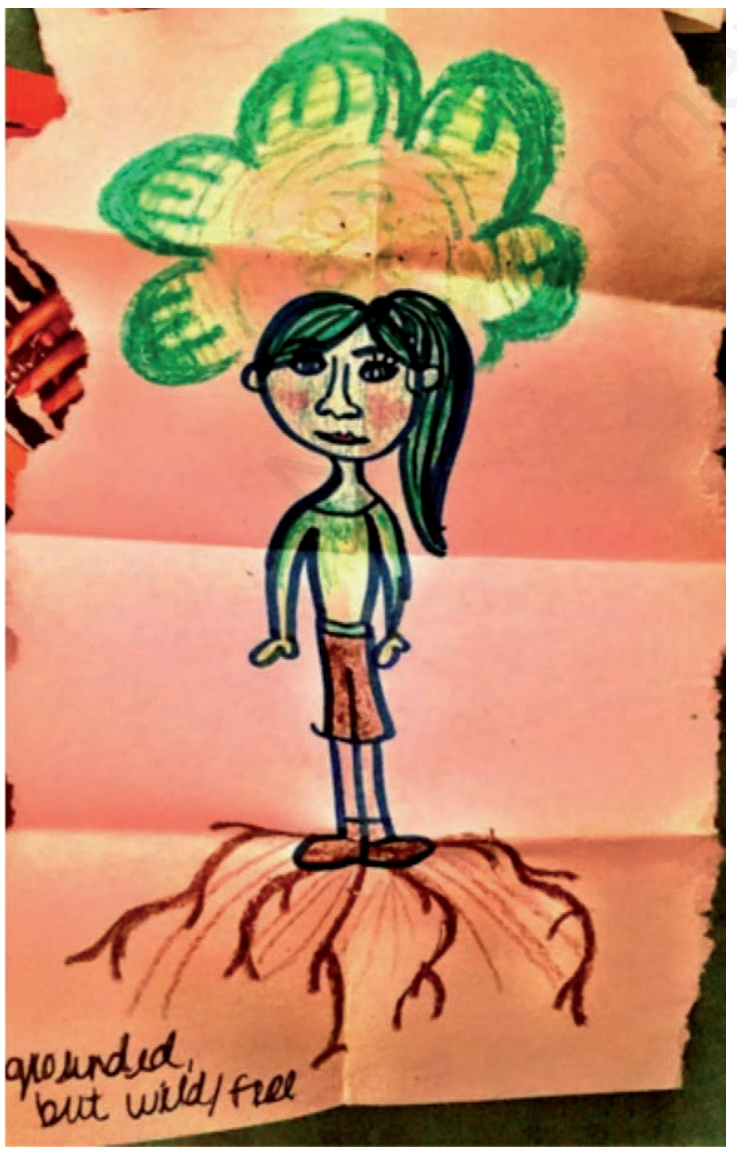

Figure 2. Picture drawn in therapy meant to depict a better self. with guilt when leaving my family in Minnesota for college in New Hampshire; but really, I was meant to share the adventure with my family through pictures, phone calls, and visits. All in dynamic balance; free, but in connection. I continue to strive for this dynamic balance between agency and obligation within my environment. Maybe freedom could be understood as moving in connection with others and our environments - an ease in breathing, letting things go, letting things in.

In the International Journal of Eating Disorders, Tozzi et al. ${ }^{15}$ discover perceived pressures and stressful experiences as common causes of eating disorders. Although I intend to stray from determining the causes of AN, I believe these findings offer insight into grander societal systems and how they construct environments. As a people pleaser, I've been highly susceptible to perceived pressures and stressful experiences; I've perpetuated societal discourses that demand people pleasing women. Trying to please people and attend to assumed/stated needs creates a complex reality of pressures, standards, and expectations known to fuel eating disorders. This way of being would not be encouraged by a balanced sense of agency and obligation. As a people-pleaser, I had completely abandoned agency and lived for obligation-I lived submissively. This way of being invited the dominance of AN.

\section{Mother and daughter}

Hepworth ${ }^{10}$ speaks to the blame that's been cast on the mother-daughter relationship. AN studies have concluded that mothers who are too involved with their daughters amplify the likelihood of AN. These studies claim that a mother's 'over involvement' creates a radical, internal struggle of independence within the daughter; in which the daughter struggles to break free from the mother and find her own way of being in the world.

An awareness of individualism, independence, control, and freedom as culturally-constructed reveal that this conclusion is culturally-coded. My experience disproves this theory; I don't believe my mother was overly involved. Especially in comparison with my friends' moms, my aunts as mothers, and my grandmother as a mother. Although my mom stayed at home, she valued raising my brother and me with a high sense of responsibility; in which we were responsible for multiple duties at a young age - getting homework done, waking up in the morning, making our own lunches, walking the dog. Later, around the time of her divorce, she struggled with depression and was not readily available; high school graduation and college application duties became my responsibilities. But on a grander scale, the ratio of over-involved mothers seems to outweigh the number of AN patients. Regardless, the conclusion continues to hold weight.

Focusing on and isolating the mother-daughter relationship ignores various other factors; so we might widen our gaze. Studies have expanded in acknowledgement of the father-daughter relationship and eating disorders in 
males ${ }^{16}$ — but I suggest going further. Instead of peering into the mother (or father) $\rightarrow$ daughter (or son) relationship and the proceeding daughter/son $\rightarrow$ world relationship, we might broaden our view to recognize a more general, dramatic shift in environments. We could explore the overall extremity of an environmental switch - where infinite factors and external pressures are involved. Environmental shifts might not entail moving physically; but environments change when the people, values, beliefs, and discourses around us change. We could become more aware of what transpires within a dramatic, environmental change (Figure 3).

\section{Intelligence}

MedScape ${ }^{17}$ features a study, as the compilation of studies, titled Higher IQ found in patients with anorexia nervosa. The study asked the question - do people with AN have a higher IQ than the general population? 30 peer-reviewed studies claimed that people with AN scored $10.8-5.9$ units above the normal population's IQ. ${ }^{17}$ Throughout therapy, the discourse of AN as intelligent circulated throughout the clinic; I took pride in this trait.

But what is intelligence? Our cultural understanding of intelligence implies the prioritization of and adherence to empirical knowledge; ${ }^{18}$ a system that reflects in AN's way of being. Garner ${ }^{8}$ interprets the typical superior academic performance of AN patients as overcompliant adaptation; dedication to the empirical way could be understood as perfectionism - which as mentioned, demands obedience to dominant discourse. Anything other than perfect/dominant is not perfect, and not okay. Garner ${ }^{8}$ understands perfectionism in AN as part of a dichotomous thinking style. This black $v s$ white, all-or-nothing thinking style seems to mimic dominant discourses that rule AN. ${ }^{8}$

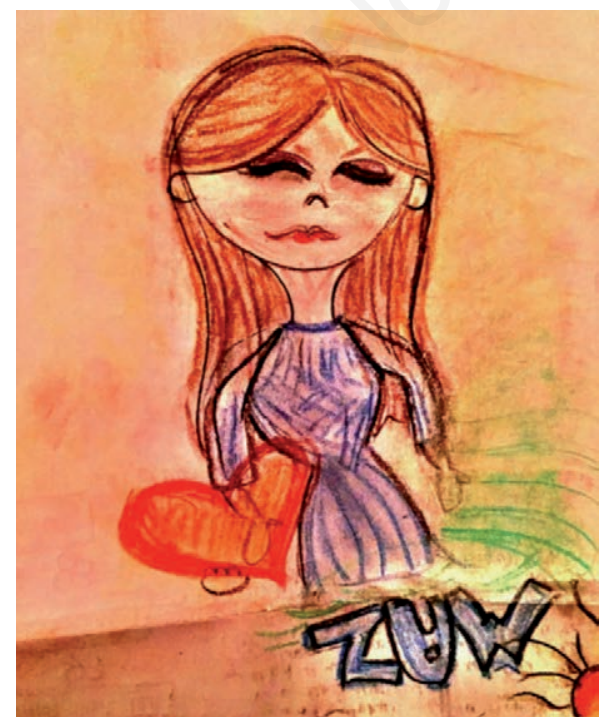

Figure 3. Picture drawn in therapy of my mom.
My strict and rigid habits implied adherence to empiricism and overcompliant adaptation to dominant discourse (not necessarily the content of dominant discourse, but an imitation of the processes in which it prevails). I now have a different understanding of intelligence - as practical wisdom. What if those living with AN were encouraged to practice practical wisdom in problem solving? Practical wisdom seems to encourage creativity and appreciation for a grand variety of solutions. If we valued practical wisdom as intelligence, we could open up the door for many goods. If we enabled practical wisdom, we might enable alternate discourses - to develop and broaden societal norms (goods).

\section{Deviance}

AN as obedient to empiricism might manifest itself in culturally-coded concepts of intelligence and deviance. Hepworth ${ }^{10}$ speaks to the deviance of those living with AN. Rather than focusing on the means by which AN might deceive therapists, family, friends - we might more deeply understand this 'deviance' not as malicious, but as the same prioritization and strict adherence to empiricism associated with intelligence. As mentioned, dominant discourse suppresses alternative discourses; the dominant presence of AN as the one way, the only way, doesn't allow for mom's voice, friend's voice, or anyone else's voice. AN doesn't allow for the coordination of multiplicities.

When confronted with difference, we tend to seek consensus - which has its problems. ${ }^{19}$ Consensus seeks common ground through negotiation and usually settles on smaller, light-weight issues rather than confront the larger areas where people are more heavily and passionately invested. ${ }^{19}$ To approach difference through the lens of coordinated multiplicities, we attempt to coordinate multiple discourses in which there's not one solution-but multiple solutions, even multi-dimensional solutions, that honor the variety in values, beliefs, and ideas. ${ }^{19}$ The goal is to find more deeply understand values and beliefs and the practices that manifest. ${ }^{19}$ What would happen if AN was confronted by the coordination of multiplicities? How can we use these concepts to create ways of being that discourage AN and destructive societal systems it perpetuates?

\section{Another way of being}

\section{The worst}

Usually, her dreams scare her. She's afraid to go to bed, to fall asleep. Her stomach grumbles and she squanders it with blankets, hoping it won't wake her roommate. She shakes a little while she waits. She tries to picture herself cradled in God's hands - comforted by a swaying lullaby. But once she crosses that realm into blackness, His hands gently slip away.

All of a sudden, she's looking down at herself from above. She's wrapped in a white hospital robe-tied at the neck and open in the back, revealing a bony, bumpy spine. 
She's sitting on a bed in a white-walled room. Her hands grip the sheets beneath the tendons of her knees, and her legs kick anxiously. Her pupils dilate and look nervously from side to side. Her eyes and teeth are sunken deep and yellowish. The corners of her lips turn slightly upward, in a sheepish grin.

She stands on the bed. Her knees bend then spontaneously expand - in an estranged jump. She giggles maliciously, jumping on the bed. A lab-coated doctor enters. The girl runs in circles, surrounding the bed. She runs and screams and the noise shrivels the ear canals of the doctor. And her mom, now in the room.

The girl from above squirms at the raw intensity. *written in starvation

AN transcended my conscious self-it permeated my dreams and deepest thoughts. I had nightly terrors of being shot, sexually assaulted, and the devil breathing. According to Elkins, ${ }^{20} \mathrm{AN}$ goes beyond the dominant discourses of beauty and normalcy - these qualities have only been considered anorectic and medically important in the last couple centuries. Basically, AN existed before skinny was the new pretty.

AN seems to embody the how and why of dominant discourse - through the ways in which both have prevailed throughout history. In the $16^{\text {th }}-18^{\text {th }}$ century, AN was considered a medical condition unrelated to beauty. ${ }^{10}$ In the $5^{\text {th }}-13^{\text {th }}$ century, it was considered a divine intervention and miracle. ${ }^{10} \mathrm{AN}$ has existed throughout time and under various ideals of beauty; furthermore, AN has existed as means toward and away from societal ideals. Therefore, AN could be explored as deviance and embodiment; overall, it participates with society.

Multiple explanations ${ }^{1,2,10}$ present $\mathrm{AN}$ as the struggle to find a way of being in the world; whether in separation from the mother, becoming an autonomous adult, rejecting independence, or a more general confusion about his/her place in society. Gergen ${ }^{7}$ and $\mathrm{McNamee}^{19}$ offer a way of being that involves the coordination of multiplicities - I began utilizing this concept in subtle ways before reading their material, and it significantly aided my continued recovery and development of a better way of being in society (Figure 4).

\section{It gets better}

When AN is a product of and agent within the environment, I am a flower-and my health is dependent on

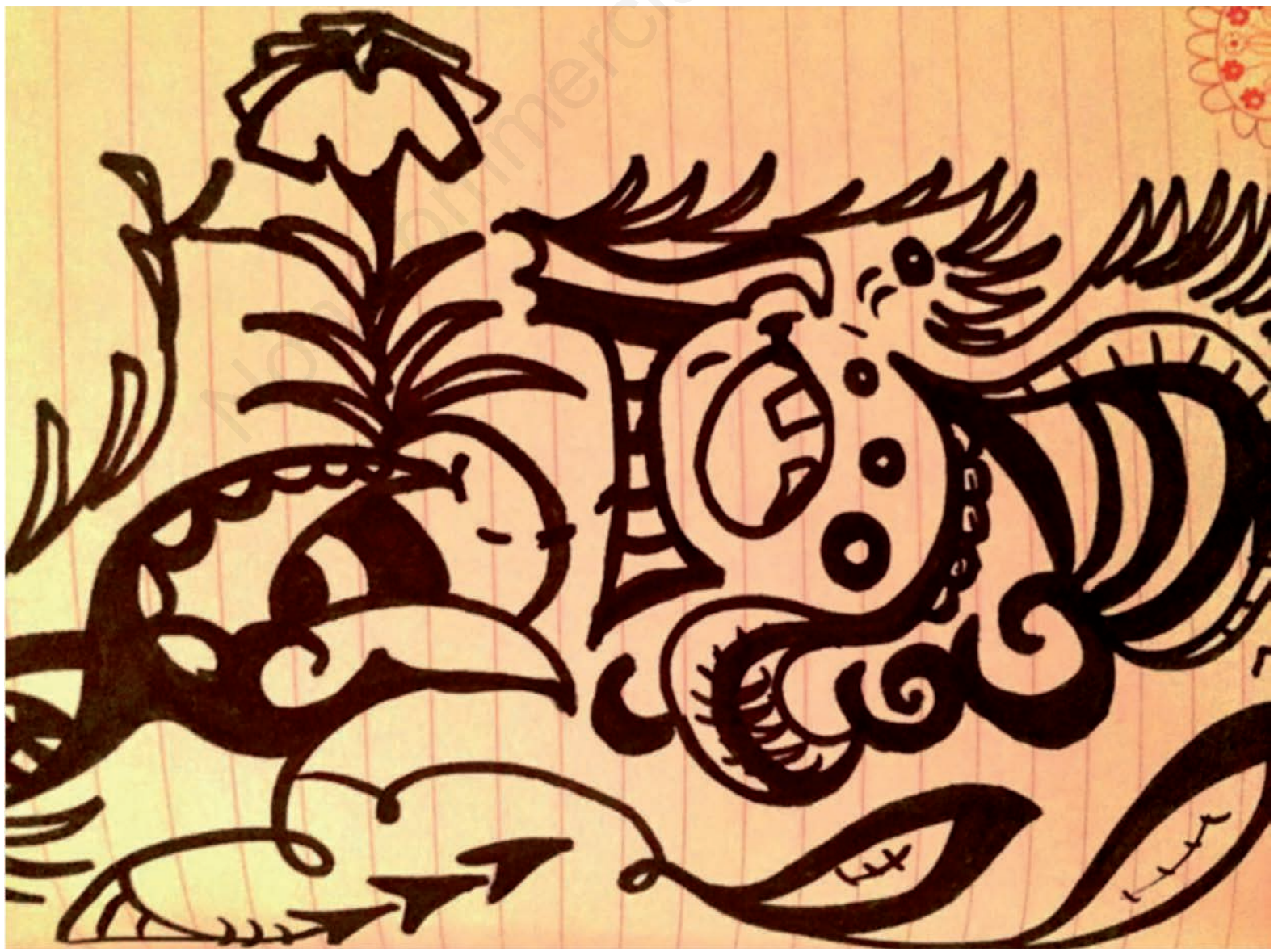

Figure 4. One of many thematic, therapeutic drawings while in recovery. 
the infinite atmospheric variables surrounding me. Recovery came to mean recreating my environment-incorporating those 'check and balance' discourses in collaboration with dominant discourse.

Above, although the roots are crazy, and different, and don't seem to belong - they fit together. They make it work; and they make an awesome image. By coordinating multiplicities, we can construct another way of being open to potential and vitality. A way of being that involves various goods, ideas, meanings - for example, I came to realize the variety of meanings involved in food. I expanded my understanding of food as individual consumption to communal participation - in which a best friend who wanted to get dinner was more important than being small or restricting or perfection. Food became justifiable. Furthermore, I became aware of the other presences that fed my soul like the isolating presence of AN never could. The coordination of multiplicities allowed me to develop a variety of goods, broaden experiences, and increase relationships; it constructed a more generative way of being. The coordination of multiplicities was one of my greatest aids in continued recovery and served as a generative antidote to a self-defeated way of being. ${ }^{6}$

Furthermore, this reconstruction does not call us to obliterate or eliminate the voice of AN. I am constantly working to balance discourses, but I've experienced new ways of being not as concerned with AN; these experiences have revealed unlimited potentials and inspiration for alternatives. We are called to keep AN in conversation, but also to question - in order to move away from heavyweighted dominant discourses in which AN thrives.

\section{Conclusions}

I hope that my story makes sense for those consumed by the demands of AN - and that he/she might be able to use similar tools in the creation of a way of being fueled by the coordination of multiplicities.

\section{References}

1. Lock A, Epston D, Maisel R. Countering that which is called anorexia. Narrative Inquiry 2004;14:275-301.

2. Chatham-Carpenter A. 'Do thyself no harm': protecting our- selves as autoethnographers. J Res Pract 2010;6:M1.

3. Water's Edge Counseling and Healing Center. Intensive Outpatient programs for adolescents and adults. Burnsville, MN: Water's Edge Counseling and Healing Center; 2017.

4. Media Education Foundation. Killing us softly 4. Media Education Foundation, Northampton, MA, USA: Media Education Foundation; 2016.

5. Sontag S. On photography. London: Macmillan; 1977.

6. Gergen KJ. Therapeutic challenges of multi-being. J Fam Ther 2008;30:335-50.

7. Gergen KJ. Relational being: Beyond self and community. Oxford: Oxford University Press; 2009.

8. Garner DM, Olmstead MP, Polivy J. Development and validation of a multidimensional eating disorder inventory for anorexia nervosa and bulimia. Int J Eat Dis 1983;2:15-34.

9. Daston L, Galison P. The image of objectivity. Representations 1992;40:81-128.

10. Hepworth J. The social construction of anorexia nervosa. J Commun Appl Soc Psych 1999;9:478-80.

11. Comaroff JA. Criminal obsessions, after foucault: postcoloniality, policing, and the metaphysics of disorder. Critic Inquiry 2004;30:800-24.

12. Foucault M, Burchell G, Gordon C, Miller P. The Foucault effect: studies in govern mentality. Chicago, IL, USA: University of Chicago Press; 1991.

13. Mayo Clinic. Scottsdale, AZ, USA: Mayo Foundation for Medical Education and Research; 2017. Symptoms and causes - Anorexia nervosa; 2017. Available from: http://www. mayoclinic.org/diseases-conditions/anorexia/symptomscauses/dxc-20179513

14. Rubel J. Eating disorder statistics. Anorexia Nervosa \& Related Eating Disorders. Available from: https://www.anred.com

15. Tozzi F, Sullivan PF, Fear JL, et al. Causes and recovery in anorexia nervosa: the patient's perspective. Int J Eat Dis 2003;33:143-54.

16. Hodges N. Weighing ourselves down. Depart Crit Qual Res 2015;4:51-69.

17. Kreimer S. Higher IQ found in patients with anorexia nervosa. New York, NY, USA: Medscape; 2010. Available from: http://www.medscape.com/viewarticle/734950

18. Semin GR, Gergen KJ. Everyday understanding: social and scientific implications. In: GR Semin, KJ Gergen (eds.) Everyday understanding: social and scientific implications, pp.1-18. Newcastle upon Tyne: Sage; 1990.

19. McNamee S. Transformative dialogue: coordinating conflicting moralities. The Lindberg Lecture. 2008. Available from: http://pubpages.unh.edu/ smcnamee/dialogue_and_ transformation/LindbergPub2008.pdf

20. Elkins J. Pictures of the body: pain and metamorphosis. Stanford, CA, USA: Stanford University Press; 1999. 